\title{
State-of-the-art of Historic Building Information Modelling - HBIM Trends in the Built Heritage - Review Paper
}

\author{
Khalid A. Hussein*, Emad Hani Ismaeel \\ Department of Architecture, College of Engineering, University of Mosul, Iraq
}

\section{ARTICLE INFO}

Article history:

Received 14 June 2020

Accepted 14 August 2020

Keywords:

HBIM; Built Heritage; 5D

Representation; Documentation; Historic Building; State-of-the-art

\begin{abstract}
Built Heritage is a significant division of cultural heritage. Thanks to their economic, symbolic, social, and cultural values, Built Heritage performs an essential task in achieving cultural distinction and promoting local identity. The paper focuses on the growing role of HBIM in the field of the Built Heritage due to the benefits of BIM systems, which are characterized by the creation of digital information models with multi-dimensions. These dimensions give HBIM an essential task in the representation of Built Heritage that defined by multi-criteria. The study seeks to determine the approaches of utilizing BIM techniques in the Built Heritage area to classify the current trends of the studies that dealt with the research problem. Also, it aims to analyse HBIM techniques that employed in the discipline of Built Heritage, highlighting the procedures and methods used in these studies and researches, underlining the integration of HBIM with other technologies (e.g. Virtual Reality-VR, Augmented Reality-AR, Artificial Intelligence techniques -AI), and determining the potential of the HBIM system in these fields. The research is established on academic studies and researches analyses that have adopted the HBIM system in the sector of the Built Heritage to present a set of conclusions for current and future use of this technology.
\end{abstract}

\section{Introduction}

Built Heritage is a vital part of cultural heritage. It plays an essential task in achieving cultural excellence and promoting local identity because of their economic, symbolic, social, and cultural values (Mahmoud,2015, P2). Hence, there is a need to adopt information systems to facilitate the exchange of information in the fields of Built Heritage (UNESCO Digital Charter, Article 16, 2004). Recently, there is a significant development in information systems, represented by the great development of the Building Information Model -BIM, which has facilitated to represent the building information within digital systems which is one of the means of the preventive conservation -which is one of the types of conservation in Built Heritage (Al-Allaf,2014, p104). The importance of this technique embodies in saving time, reducing costs, simplicity, reducing errors and inconsistencies, and the possibility of analysing information in these models (LAHDOU,2011, p10-12). The technical development of BIM systems has been reflected by specialists using several features from ordinary BIM systems in "Heritage Building Information Modelling Systems" or "Historic Building Information Management Systems".

This study is a systematic literature review aims to determine the role of HBIM in Built heritage to define its methodology in each trend by determining the techniques, Standards,

\footnotetext{
* Corresponding author. E-mail address: khalid.ahmed@uomosul.edu.iq DOI: $10.24237 /$ djes.2020.13308
} 
Types, Scope, and applications, thus, the additional knowledge is represented in presenting the main trends of HBIM by its future potentials with other technologies that integrate with it in various fields and purposes of architectural heritage from urban scale to buildings and heritage elements, then provide general recommendations that enhance the employment of HBIM in the built heritage.

\section{Methodology}

The Study adopts an analytical study of a set of researches that focused on the role of historic buildings information modelling-HBIM in the Built Heritage to determine its methods, scope of studies, and technologies used in BIM systems, besides classifying these studies according to research's trend and purposes.

\section{Theoretical framework}

\subsection{Previous studies}

Several academic studies and research were chosen as a case study from the latest studies related to the HBIM that collected by searching keywords in academic journals dealing with built heritage, in addition to searching in search engines of scientific academies of universities, colleges and institutes architectural to cover all aspects, purposes and technologies of HBIM in the built heritage. So, in this paper, 29 studies and researches are analysing, including 14 doctoral dissertations, 7 master thesis and 7 research papers specialized in the field of the Built Heritage. In this part, these studies are described in terms of the research trend, its techniques, and the role of HIM as follows:

1. Murphy,2012: This PhD study used HBIM to produce preservation documents for combining survey data to create 3D objects based on the Shape Grammar system using Geometric Descriptive Language (GDL) to build a parametric library of architectural elements. Next, programming a new shape grammar with parameters linking them to GIS and City GML.

2. Alitany,2013: The research focused on the 3D modelling approaches based on digital imaging, and DSM techniques using the Digital Photography, 3D modelling, PMS and Rhinoceros programs to document heritage elements.

3. Baik A,2013: The research aims to create an interactive library of heritage elements controlled by Shape Grammar that used in the documentation, restoration, education and information exchange.

4. Holden,2014: The Master thesis focuses on the fundamental role of HBIM by combining traditional methods with modern technologies to develop urban conservation practices.

5. LOSTAFFA,2014: This Master thesis evaluated the use of BIM models for analysing changes in significant heritage buildings to achieve different assessments on a 4D model formed in virtual or augmented reality.

6. Baik B,2015: The research focused on the integration between HBIM and GIS for the documentation and management the historic buildings.

7. Barazzetti,2015: The study offered an approach in heritage preservation with a sustainable management by integrating HBIM with other technologies.

8. Dore A,2015: The research used Shape Grammar for HBIM heritage architectural elements based on previous studies and documents.

9. Quattrini,2015: The research aims to develop a high-quality 3D model to link historical survey data with a database to create HBIM models containing comprehensive information for the preservation .

10. Worrell,2015: The Master thesis focused on the significance of BIM for management of Urban Heritage in an interactive platform.

11. Mandelli,2016: The $\mathrm{PhD}$ study highlighted the multi-dimensional models in real scale to transfer data from reality to other concerned fields.

12. Pomini,2016: This Master thesis emphasized the importance of BIM methodology in archaeology.

13. Bertolini,2017: The PhD study draws the utilizing of HBIM approaches for historic 
buildings restoration by determining the level of detail (LOD) and creating parametric HBIM libraries for reusing objects in new contexts.

14. Davardoust,2017: The PhD study focused on the uses of VR/AR technology in the BIM to exchange data in the fields of construction in a unified archive.

15. Dore B,2017: In this $\mathrm{PhD}$ study, an integrated procedural methodology was developed to support the modelling processes of historic buildings using HBIM to develop a set of rules-algorithms using geometric descriptive languages (GDL to the generate facades according to the shape grammar.

16. Nicastro,2017: The PhD study examined the reliability of digital models in the HBIM environment to ensure the accuracy of displaying heritage buildings information, in addition to an interactive environment that brings together Built Heritage professionals with libraries.

17. Yulie,2017: This PhD study emphasized on the importance of diagnosis and reuse of heritage buildings by the BIM. Because these diagnoses are vital for diverse professionals in the field of curative conservation for identifying the status of reusing heritage buildings.

18. Annie,2018: This Master thesis determines the BIM features in documenting and managing in 5D models to create the HBIM models.

19. BOVI, 2018: The PhD study dealt with the deterioration of heritage buildings in Italy to suggest an effective and sustainable approach that provides the information necessary for maintenance, restoration, and rehabilitation.

20. Bruno,2018: The PhD study presented a methodology for automating the diagnostic of heritage buildings by algorithms based on digital database diagnoses of the deterioration and failures.

21. Damiani,2018: The Master thesis presented tools and methodologies of BIM with Virtual Reality as a tool management actions of historic sites.
22. Eleonora,2018: The Master thesis concentrated on the employment of contemporary technologies for enhancing a participatory information platform for heritage buildings using Virtual Reality.

23. López,2018: The PhD study focused on the digital representation of heritage buildings in HBIM models of geometric, semantic and topological information from "Cloud Points" that taken by Laser Scanning.

24. Rolin,2018: This PhD study focused on current techniques and data processing based on HBIM parametric models in the field of structural analysis.

25. Sheng,2018: The PhD study focused on the organization of survey data of heritage buildings using Stochastic Point-Based Rendering (SPBR) based on laser scanning data.

26. Yang,2018: This Ph.D. study explores the concept of HBIM for lost heritage by converting traditional models into HBIM parametric models.

27. Banfi A,2019: This Ph.D. study focused on creating an interactive platform that enhances interoperability between specialists in the Built Heritage field.

28. Banfi B,2019: The research highlights the modelling standards of heritage buildings such as level of detail, degree of accuracy, and degrees of generation.

29. Brioso,2019: The research presents an approach for the management of the urban heritage according to the Lean Construction methodology that deals with the mechanisms of intervention and maintenance.

\subsection{Classifying main trends of HBIM}

The main trends of HBIM can be determined from previous studies according to its methodology in dealing with information and its purpose. Each trend shares procedures, applications and techniques in that make a trend distinguished from other, therefore, HBIM trends can be classified into:

1. HBIM trend in the Modelling techniques

2. HBIM trend as a participatory Platform. 
3. HBIM trend in analytical studies.

4. HBIM trend in Management.

5. HBIM trend in the Restoration operations.

6. HBIM trend in the Documentation.

\subsection{Determining the variables}

From previous studies, several variables including modelling techniques, digital techniques, standards, scopes, and applications are repeated in some procedure of the studies, these variables define the HBIM methodology in each trend, also these main variables contain sub-variables as follows:

\subsubsection{Modelling techniques:}

1. Solid Modeling uses primary elements (such as a sphere, a cube, and surfaces) in the process of representing models by modification operations on these elements.

2. Procedural modelling is Modelling Techniques generates models automatically based on a set of rules (such as digital shape grammar ).

3. NURBS is a technique based on generating models with complex and curved surfaces using mathematical equations..

4. Stochastic Point-Based Rendering (SPBR) is a modelling technique based on creating models with a transparent effect, based on a stochastic algorithm that deals with the cloud points from the scans.

\subsubsection{Data collection techniques:}

1. Traditional Methods.

2. Laser Scanning : Process of scanning models from reality to form accurate models based on point cloud.

3. The Photogrammetric survey:Methods of data collection and modeling, this technique depends on high-resolution images to form models by overlay these images in high accuracy.

\subsubsection{Architectural styles}

1. Shape Grammar :A Set of rules and grammar that generate shapes or designs according to a specific architectural style or language.

2. HBIM Libraries are a constructive database characterized by storing, organizing, collecting and integrating objects with pre-defined parameters.

\subsubsection{Programming techniques}

1. Interoperability : This term refers to the ability of computer systems and applications to exchange information in different formats, and it explains information sharing between different systems.

2. Programming Language is a technique of representing the data using computational algorithms, this includes many types of language :

a. Web Ontology Language (OWL): a Formal Programming language for classifying elements and defining their structure.

b. Geometric Descriptive Language (GDL) is a programming language represents $3 \mathrm{D}$ and $2 \mathrm{D}$ elements using a set of programming formulas.

c. CityGML is a model for representing data of urban and cities and exchange this dara with many programs and application.

\subsubsection{Technologies}

1. $V R, A R, M R$ :

a. Virtual reality (VR) is Simulating a number of characteristics or in a digital world as it is in reality using computer technologies.

b. Augmented reality (AR) is an An interactive experience in a real world by dealing with the elements in it using a computer.

c. Mixed reality (MR) is the merging of real and virtual worlds to produce new environments and visualizations.

2. Geographic Information System (GIS) is one of the techniques for dealing with geographical data for cities, which 
provides analysis, distribution and representation of this data using several computer applications for specific purposes.

3. BIM Mobile: One of the BIM technology, which provides the ability to display and handle information by mobile devices.

\subsubsection{Standards}

1. Level of Detail (LoD) is the level of information representation in models with multiple levels, starts from twodimensional representation to higher levels of representation in as built.

2. Grades of generation (GOG) A standard that defines the mechanism of the model, which determines the level of information and dealing with various data.

\subsubsection{Applications}

1. Dynamo is an application that depends on the BIM system in conceptual and parametric design.

2. Rhinoceros is A program for 3D representations and modelling, it depends on the NURBS methodology to create an accurate models with curved and complex surfaces.

3. Revit is one of the important information modelling software in $3 \mathrm{D}$ and $2 \mathrm{D}$ models.

\subsubsection{Scope}

1. Urban: Dealing with urban scale.
2. Building: Dealing with individual heritage buildings.

3. Element: Dealing with architectural elements.

\subsubsection{Performance}

This variable deals with building performance and is related to periodic diagnostics.

\section{Analysing the studies}

Previous studies are grouped according to the trends of HBIM that were previously determined according to its purpose and procedure, followed by an analysis of each trend using the variables that have been identified. The analysis has used a matrix to determine the techniques, standards and applications used in each methodology of a trend as shown in Table 1. In another matrix, Quantitative-Earned Scores Based on The Methodology are determined in percentage to show the importance of each variable in each trend as shown in table 2. Then, a linear mathematical chart of the variables used in analyzing studies is used to determine the methodology used in the six HBIM trends.

\section{Results}

The results show the existence of specific main trends of HBIM in dealing with information of built heritage, each trend is distinguished by its methodologies based on specific technologies and applications within a specific scope of built heritage 
Table 1 A matrix identifies the applications, techniques, and methodology used in the literature of HBIM

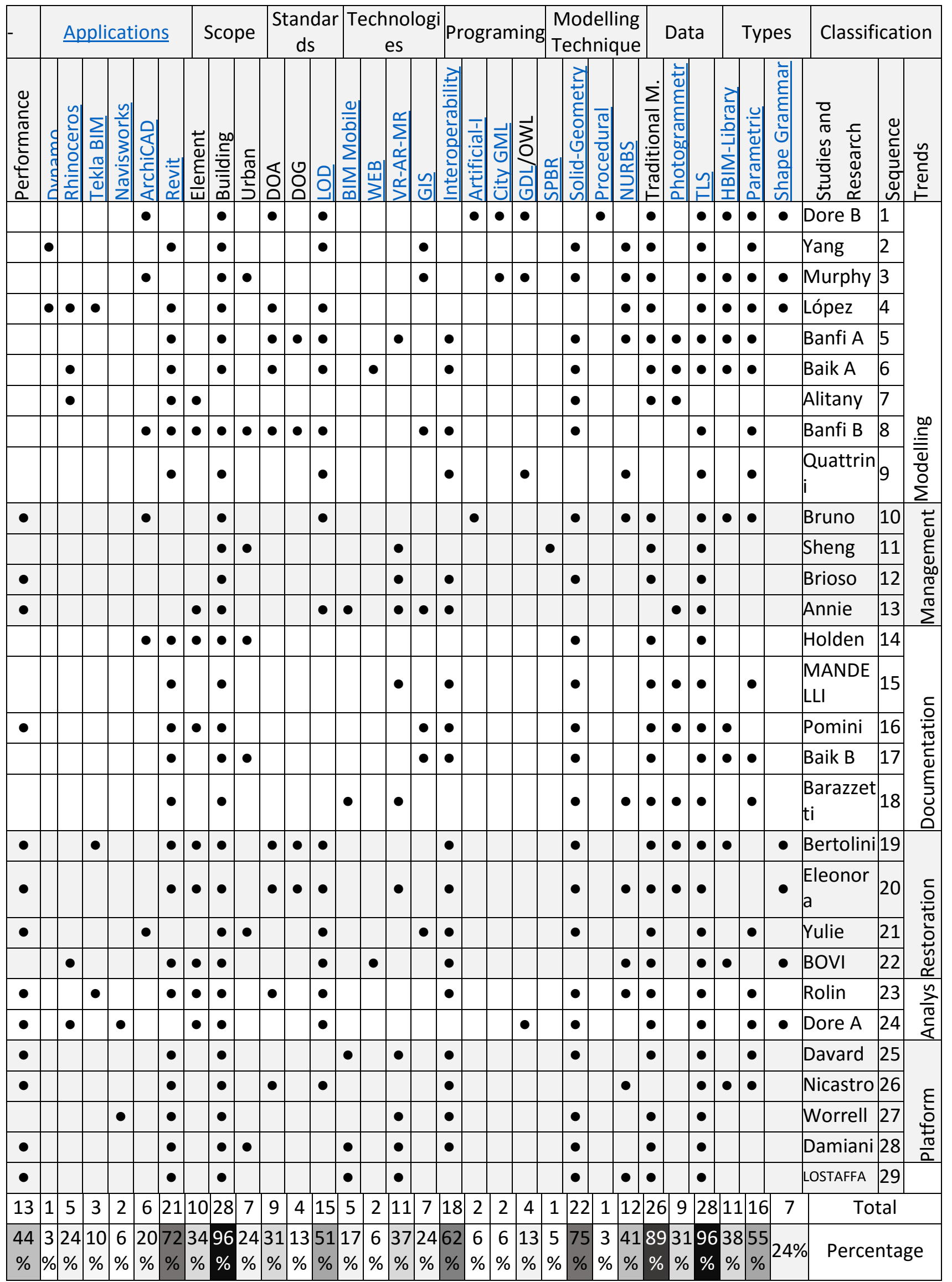


Table 2 A matrix shows the quantitative-earned scores based on the methodology and the classification by content for the previous studies within HBIM

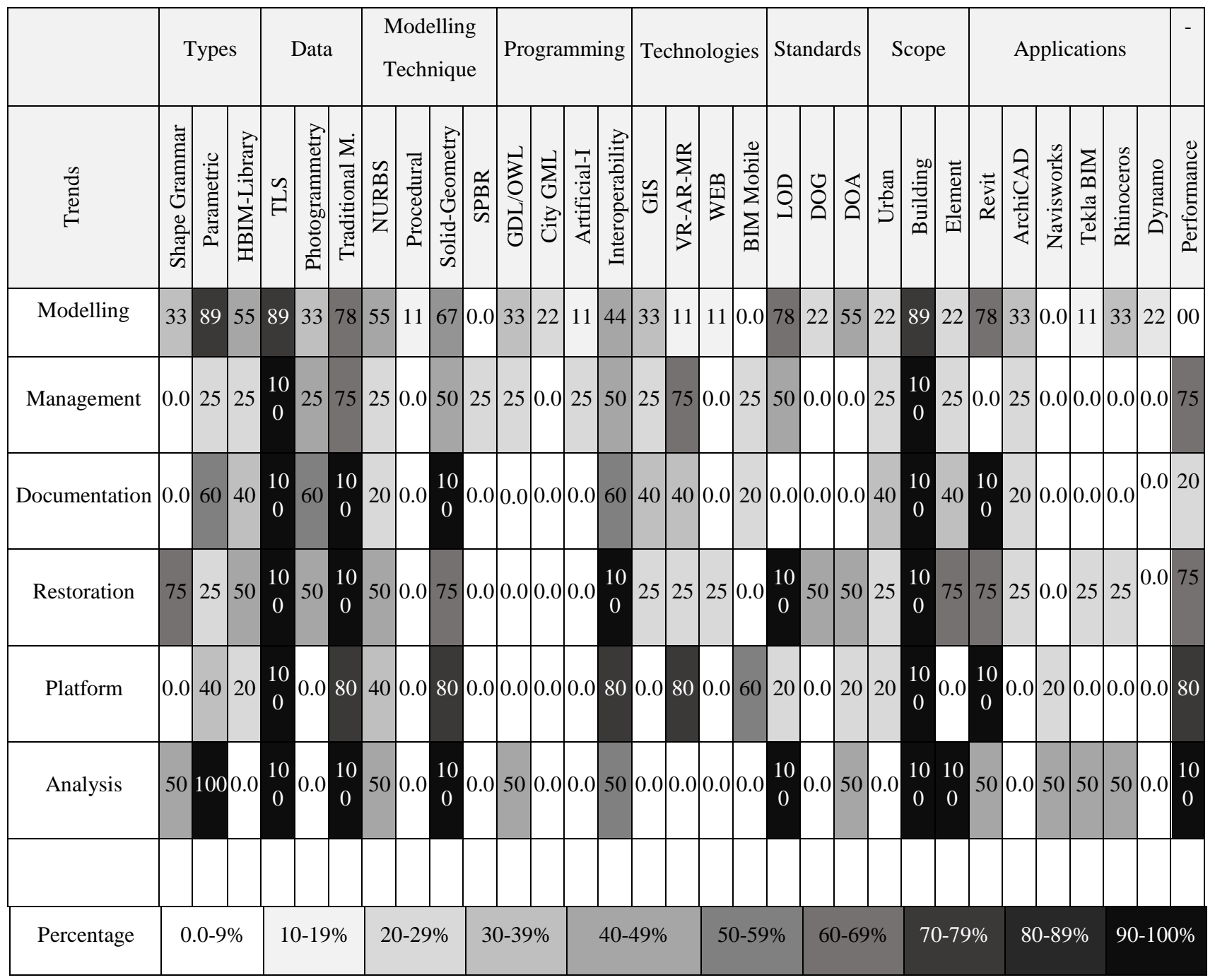




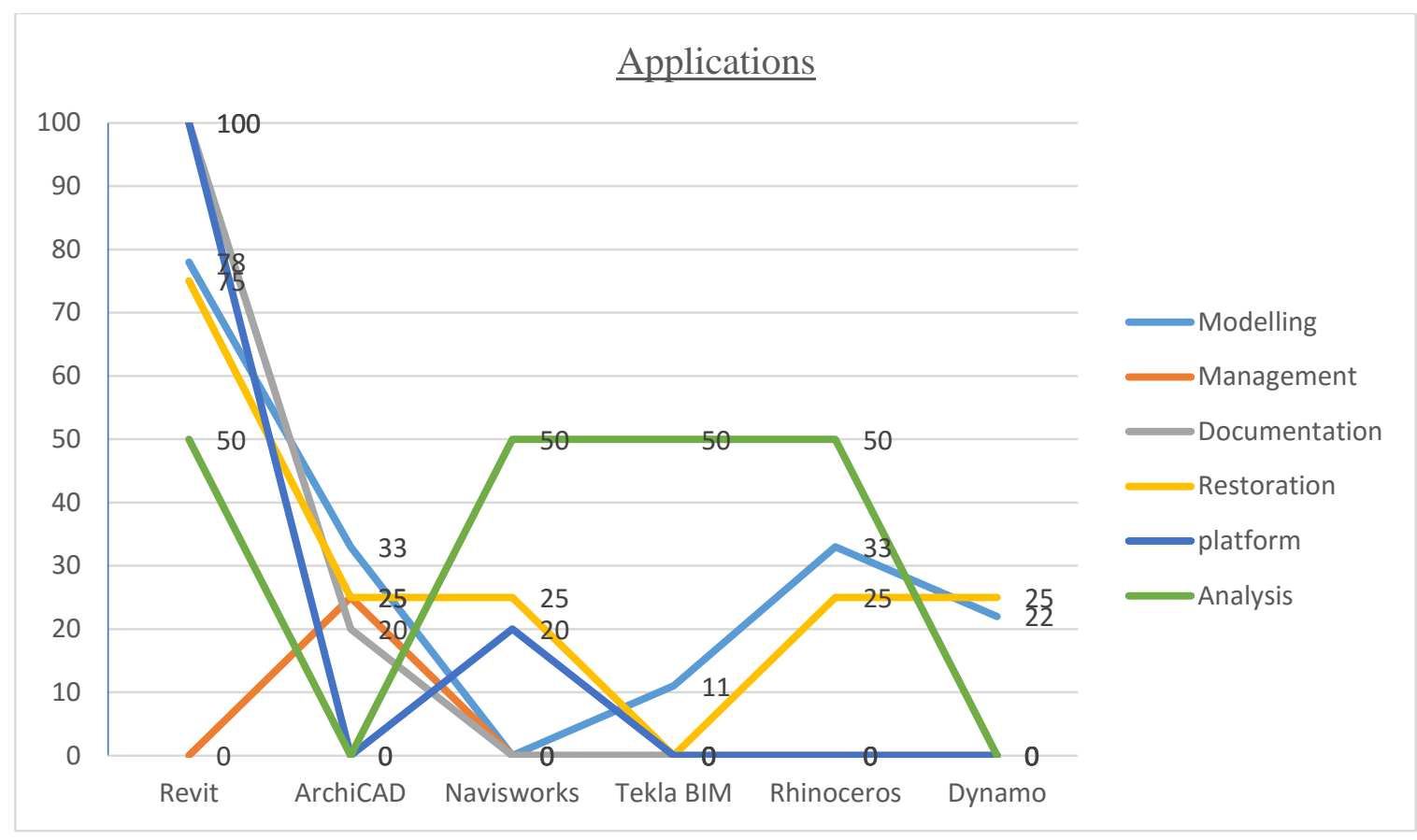

Fig. 1. Diagrams show the trends of the methodology of HBIM in the current literature based on the assessment variables
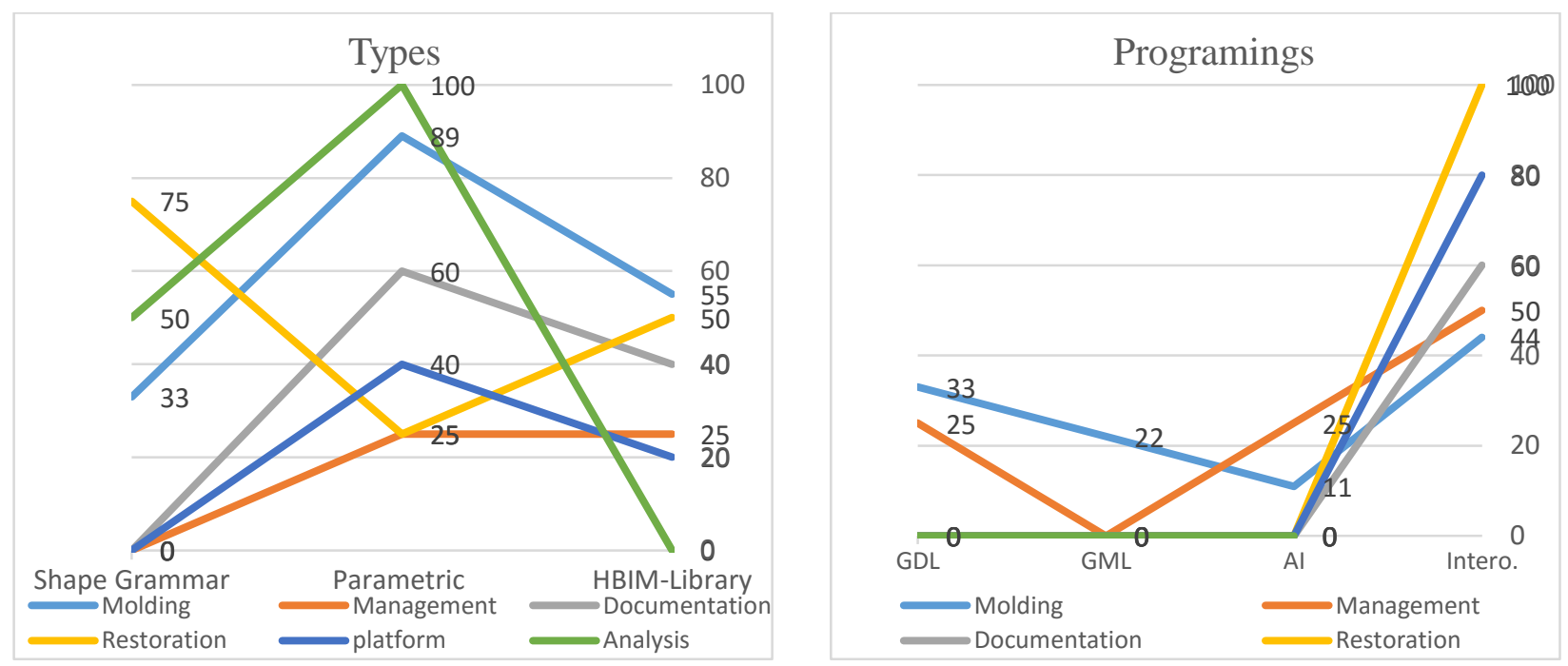

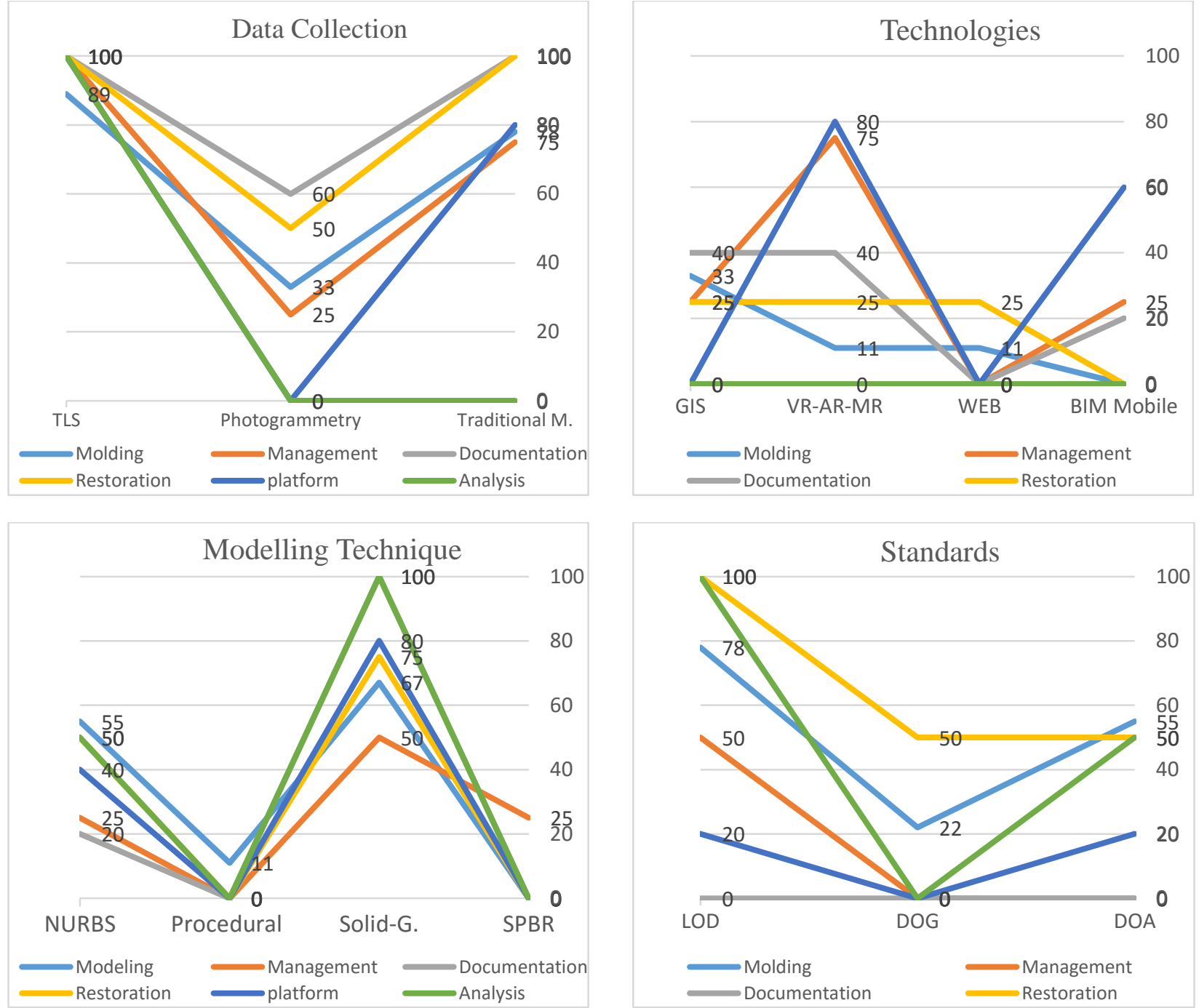

Fig. 2. Diagrams show the trends of the methodology of HBIM in the current literature based on the assessment variables

\section{Discussion}

Aforementioned, several aspects of findings and results can be discussed as follows:

1. Identification of the six main trends of HBM in the Built Heritage field:

1.1. Modelling of heritage buildings: several studies in this trend focuses on the shape grammars, architectural styles and the formation of parametric libraries. also, Solid Geometry was adopted as a method of modelling; while NURBS was adopted in the studies that focused on complex historic structures. Some studies have used AI applications to regenerate missing parts using GDL or OWL descriptive programming languages.

1.2. Building management and performance monitoring: these studies concentrated on individual buildings, using algorithms to manage the life cycle of historic buildings and evaluate the performance of these buildings.

1.3. Documentation of historic buildings: These studies formulate a library of heritage elements, from data survey methods such as Photogrammetry and Laser Scanning. Most of these studies take an individual building as a case study and neglects the urban level and the context of the buildings. 
1.4. Participatory information environment (platform): These studies employ virtual and augmented reality technologies, and use a parametric library to provide information to link the models with the WEB network.

1.5. Restoration the elements (the curative conservation): These studies analysis architectural styles books to formulate shape grammars to determine the restoration processes, in addition to the creation of digital libraries of heritage elements. The scope of these studies is an individual element.

1.6. Analytical studies of historic models: this trend of studies employ HBIM as simplified models (were most in Solid Geometry) for structural elements studies, thermal and energy studies for buildings to give more reliable values for evaluation the heritage buildings.

2. Historic styles of heritage buildings:

2.1. Most of the studies have created a parametric library of HBIM containing heritage elements for a specific historic period.

2.2. Another Study adopted references and architectural books of styles to derive the shape grammar of heritage elements.

3. Collection data techniques

3.1. The Laser Scanning method is the most used because it gives high accuracy data in a short time.

3.2. Photogrammetry is an easy and inexpensive technique of collecting data, but the models that made from this method are surfaces with little information.

3.3. Historic references and documentation books were used to study the style of elements and the changes that may have occurred on them.

4. Modelling Technique

4.1. NURBS Modelling has been used in the complex elements that required a high level of detail, and Rhinoceros programs were used in this Modelling as software.

4.2. Procedural Modelling was used in the study of Dore, which introduced a new concept of automatic Modelling using descriptive languages to create models that have rich information.

4.3. Most studies have used solid geometry (SG) for Modelling, which consists of layers containing information about the element, and Revit is one of the most applications that use SG.

4.4. Stochastic Point-Based Rendering (SPBR) has been used in studies that give information about the missing heritage elements, and it has been used in the platforms between specialists because it provides a lot of information in real-time.

5. Suppurative Techniques used with HBIM models

5.1. GIS has been used in some studies in the urban scope, because it has great potential to include information, in addition to its potential in management.

5.2. Virtual and Augmented Reality techniques have been used in several studies to create an interactive platform for conservation.

5.3. WEB used to provide HBIM library for experts, professionals, and architects.

6. Level of Detail: The Level of Detail (LoD) is related to the degree of information (LoI), the degree of accuracy (DoA), and the degree of generation (DoG). So, the level of detail was 500 in the studies that focused on the details of the elements, and LoD decreases in the greater scope of the study of the buildings and the urban level, which has an LoD value about 100 .

7. The scope of the study: because HBIM is primarily designed for buildings, most studies were for historic buildings level, while several studies focused on the urban heritage level, which linked the GIS to HBIM through language GML. A number of studies related to restoration focused on heritage elements. 
8. The Applications and the Software

8.1. Revit is the most widely used application, due to its ease of use, and high interoperability.

8.2. ArchiCAD was the second software, and it has been used extensively in studies that use programming languages

8.3. Rhinoceros program was used to modify the models of the collection of cloud points because it has the required Modelling tools.

8.4. Tekla BIM program was used in the structural analytical studies of heritage elements.

9. Potentials and limits

Despite the great potentials of employing BIM in the representation of built heritage, some obstacles can be weaknesses in built heritage, and below are some aspects of strength and weakness in the role of HBIM in built heritage:

9.1. The limits of BIM in the built heritage

- Currently, BIM tools and its libraries focus on the design of new buildings only, and there are no libraries for built heritage, so it requires creating a new library for historical styles defined by specific characteristics returns to a specific period of time.

- Weakness automation of the process to convert cloud points to parametric models because it is a long and costly process.

- All objects in the HBIM libraries must create Parameters for them to facilitate the process of modification by users.

- The absence of uniform standards for Modelling heritage elements in parametric design due to the Modelling process differ in purpose, the accuracy of details, degree of detail, and others.

- The interoperability of the BIM model needs to be improved with new technologies and programs.
9.2. The Potentials of BIM in the built heritage

- Efficiency of building information Modelling in simplifying the data and converting it into models that can be easily dealt with by all the specialists in the built heritage.

- The ability of BIM to represent architectural styles in parametric libraries for heritage elements. (this is the only way to do that).

- The ability of BIM to represent various information, such as semantic, relational, and morphological information.

- The ability of BIM to analyse quantitative and qualitative information in BIM models such as structural and energy analysis, and convert analysis data to other applications.

\section{Research implications}

It is clear from the studies that the trend is towards the automation of processing information and data of built heritage, and it is expected that HBIM will employ in the aspects of conservation, restoration, and consolidation that accompany built heritage conservation, Therefore, the research recommends the following aspects to enhance the role of HBIM in built heritage:

- Employing the Parametric modelling in the processes of modelling heritage elements, which facilitate the adaptation of their proportions mathematically to reuse them in a new context with the same architectural language of the built heritage.

- Enhancing the integration between BIM and GIS systems, which facilitates the creation of 3D models that combine the features of the two systems, although there are some problems related to the mechanism of information representation and exchange in the two systems, but the integration between 
making an interactive platform combines the features of the GIS system in the representation and analysing the spatial information with the features of the BIM system, which has a great potential in modelling information and creating parametric models. Both systems provide the capabilities of energy consumption simulation, structural analysis and numerous analyses at the urban level.

- BIM systems use pre-configured libraries for design and construction, and these libraries lack heritage elements due to their diversity, so it is proposed to create a specific library for each architectural style to bridge the technical gap for architects and specialists in built heritage.

- Unify the standards of the Modelling process in programs by providing tools that facilitate the Modelling, especially with complex elements, to avoid losing detail.

- The Multiplicity of applications that adopt the BIM system in the representation of information for various purposes makes the process of information exchange difficult for multiple applications, so research proposes to enhance the interoperability between different systems that adopt the BIM system to reduce the dependence on the intermediate applications that cause information loss.

- Despite various researches that deal with the conversion of cloud points from laser scanning to models within the HBIM, there are many difficulties regarding the level of accuracy, the large size of data, the research suggests automating the process of converting data from laser scanning to parametric models by employing artificial intelligence applications that determine Cloud points to represent elements without losing data.
- In Modelling of complex or irregular heritage elements, laser scanning and photogrammetry techniques must be employed, especially in documentation processes that require a high level of LOD detail to achieve a high degree of accuracy in the modelling process.

\section{Conclusions}

By analysing a set of studies, the researchers highlight the valuable role of HBIM in the field of the Built Heritage. In general, the task of this technique embodies in six major trends and directions including the Modelling of the Built Heritage and presentation of different types of semantic, relational and morphological information; the trend of using the HBIM as a platform that brings together specialists in built heritage, which focused on the interoperability between these experts in addition to supporting interoperability between programs and applications for information exchange; HBIM as management and controlling tool of the Built Heritage; HBIM in structural and energy analysis studies of Built Heritage; the role of HBIM in the documentation in models to represents semantic and morphological information of the elements in the built heritage; and using HBIM in the restoration of heritage elements.

HBIM technique enhances these trends by the integration with other technologies and tools, such as Virtual Reality (VR), Augmented Reality (AR), Artificial Intelligence techniques (AI), Geometric Descriptive Languages (GDL), Geographic Information Systems (GIS), web technologies, and other techniques that improve the need of HBIM in the Built Heritage sector.

\section{Acknowledgment}

The researchers thank and appreciate the specialized committee for discussing the research in the Department of Architecture, College of Engineering, University of Mosul, 
for their valuable suggestions and critical and strengthened observations to the level of scientific research.

\section{References}

[1] Al-Allaf, Emad, Preventive Conservation as a Procedure for Safeguarding Mosul Built Heritage, Diyala Journal of Engineering Sciences 07(2014) $89-198$.

[2] Alitany, A., Rebondo, E., \& Adas, A., The 3d Documentation of Projected Wooden Windows (The Roshans) in the Old City of Jeddah (Saudi Arabia) Using Image-Based Techniques, ISPRS, Remote Sens- Spatial Inf. 7 (2013) 7-12.

[3] Annie, WU Yi', Building Information Modelling for Conservation: A Feasibility Study of a Mobile HBIM Application in Heritage Conservation Process in Hong Kong, Ph.D. Dissertation, University Hong Kong, Hong Kong, China, 2018.

[4] Baik, A., Boehm, J., \& Robson, S., Jeddah Historical Building Information Modelling "JHBIM" Old Jeddah - Saudi Arabia, Remote Sens-Spatial Inf. 73(2013) $73-78$.

[5] Baik, B., Yaagoubi, R., \& Boehm, J., Integration of Jeddah Historical BIM and 3D GIS for Documentation and Restoration of Historical Monument, Remote Sens- Spatial Inf. 29 (2015) 29-34.

[6] Banfi A, Fabrizio, Holistic generative Modelling process for HBIM, Ph.D. Dissertation, Dep. of Architecture, Politecnico Di Milano, Milano, Italy,2019.

[7] Banfi B, F., The Integration of a Scan-To-HBIM Process in BIM Application: The Development of an Add-in to Guide Users in Autodesk Revit, Remote Sens- Spatial Inf 141(2019) 141-148.

[8] Barazzetti, L., Banfi, F., Brumana, R., Oreni, D., Previtali, M., \& Roncoroni, F., HBIM and Augmented Information: Towards A Wider User Community of Image and Range-Based Reconstructions, Remote Sens -Spatial Inf. 25(2015) 35-42.

[9] Bertolini, Francesca, HBIM per ilrestauro della ex chiesa di San Quiricoall 'Olivo a Lucca, Ph.D. Dissertation, Università DegliStudi Di Pisa, Italy, 2017.

[10] BOVI, MIRKO, Dalla nuvola di punti al modello BIM. Caso studio: la Villa medicea di Poggio a Caiano", Ph.D. Dissertation, Politecnico Di Milano, Milano Italy,2018.
[11] Brioso X., Aguilar R., Calderón-Hernandez C., Synergies Between Lean Construction and Management of Heritage Structures and Conservation Strategies - A General Overview, Structural Analysis of Historical Constructions 18(2019) 2142-2149.

[12] Bruno, Silvana, The implementation of automatic diagnostics and monitoring towards DiagnosisAided Historic Building Information Modelling and Management, Ph.D. Dissertation, University Politecnico Di Bari, Italy. 2018.

[13] Damiani, Giacomo, HBIM e VR per ilpatrimonio culturale: ilcaso studio del Castello di Serralungad'Alba, Master Thesis, Politecnico Di Torino, Italy, 2018.

[14] Davardoust, Sanaz, The BIM process for the architectural heritage: New communication tools based on AR/VR, Ph.D. Dissertation, Politecnico di Torino, Italy ,2017.

[15] Dore A, C., Murphy, M., McCarthy, S., Brechin, F., Casidy, C., and Dirix, E., Structural Simulations and Conservation Analysis -Historic Building Information Model (HBIM), Remote Sens- Spatial Inf. 351(2015) 351-357.

[16] Dore, Conor, Procedural Historic Building Information Modelling (HBIM) For Recording and Documenting European Classical Architecture " Ph.D. Dissertation - Dublin Institute of Technology, Dublin, Ireland, 2017.

[17] ELEONORA, FERRARETTI, Dalla nuvola di punti al modelloBIM:conservazione e divulgazion edeidati dei benistorico -culturali. Caso studio: la Villa medicea di Poggio a Caiano", Master Thesis, Politecnico Di Milano- Milano, Italy, 2018.

[18] Holden, Marla, From HABS to HBIM: The Use of Building Information Modelling for Historic Preservation Projects", Master Thesis, Florida University, Florida, USA, 2014.

[19] LAHDOU, RIM, BIM for Project Managers, Master Thesis, Technology CHALMERS University of Technology, Goteborg, Sweden, 2011.

[20] López, Facundo, Reconstrucción Tridimensional Del Patrimonio Arquitectónico Mediante La Utilización De Los Sistemas Bim Y HBIM, Ph.D. Dissertation, la Universidad de Valladolid, Valladolid, Spain, 2018.

[21] LOSTAFFA ,FRANCESCO, HBIM vs augmented information a partiredairilievi di Castel Masegra ,Master Thesis, Politecnico Di Milano, Milano, Italy, 2014. 
[22] Mahmoud ,Wahda, The Catalyst Historic Building in Urban Development, Journal of Engineering and Technology 33(2015) 97-116.

[23] MANDELLI, ALESSANDRO, Surveying, modelling and management of Cultural Heritage. Definition of good practices through applications on monuments and artworks" Ph.D. Dissertation, Politecnico Di Milano, Milano, Italy ,2016.

[24] Murphy, Maurice, Historic Building Information Modelling (HBIM) For Recording and Documenting Classical Architecture in Dublin 1700 to 1830 , Ph.D. Dissertation, College Dublin, Dublin, Ireland, 2012.

[25] Nicastro, Saverio, L'integrazione deisistemi di Building Information Modelling neiprocessi di conoscenza del PatrimonioCulturale, Ph.D. Dissertation ,University di Roma , Roma ,Italy, 2017.

[26] Pomini, Martina, UtilizzoDelbini Campo Archeologico: Ritrovamenti Di Linea 6 Della Metropolitana Di Napoli Inpiazzacomune, Master Thesis, Politecnico Di Milano, Italy, 2016.

[27] Quattrini, R., Malinverni, E. S., Clini, P., Nespeca, R., and Orlietti, E., FROM TLS TO HBIM. High Quality Semantically-Aware 3d Modelling of Complex Architecture, Remote Sens- Spatial Inf 367(2015) 367-374.

[28] Rolin, Raphaël, Contribution à une démarche numérique intégrée pour la préservation des patrimoinesbâtis", Ph.D. Dissertation, de l'Université de Technologie de Compiègne, France, 2018.

[29] Sheng, WANG, 立命館大学大学院情報理工学 研究科情報理工学専攻博士課程後期課程, Ph.D. Dissertation, Ritsumeikan University, Kyoto, Japan ,2018.

[30] Worrell, Laura, Building Information Modelling (BIM): The Untapped Potential for Preservation Documentation and Management, Master Thesis, Clemson University, Clemson, USA, 2015.

[31] YANG, Xiucheng, 3D Modelling of Built Heritage: From Geometric Models To HBIM, pour obtenir le grade de - Docteur de l'université de Strasbourg, Strasbourg, France, 2018.

[32] Yulie, Hisi, Synagogue in Pomponesco: survey, diagnosis and adaptive reuse using BIM, Ph.D. Dissertation, Politecnico Di Milano, Italy, Milano, 2017 